https://doi.org/10.46344/JBINO.2020.v09i05.32

\title{
HYDROGEN PEROXIDE AS A REMEDY FOR BRUISING- REVIEW PAPER
}

bruises

-Intradermal injection of an alkaline solution of hydrogen peroxide immediately discolors

1,3A.L. Urakov*, 2N.A. Urakova and ${ }^{3}$ A.A. Gadelshina

\begin{abstract}
1Department of Modeling and Synthesis of Technological Structures Udmurt Federal Research Center of the Ural branch Russian Academy of Sciences; ${ }^{2}$ Department of Obstetrics and Gynecology and ${ }^{3}$ Department of General and Clinical Pharmacology Izhevsk State Medical Academy of the Ministry of health Russian Federation, Izhevsk, Russia - 426034
\end{abstract}

\section{E-mail: urakoval@live.ru}

\section{ABSTRACT}

The review shows that in recent years, new cosmetics for bruises have been invented. Developed drugs can urgently discolor the skin and nail plate in the area of bruises and/or hematomas. It was found that the main skin colorants in the area of bruises are hemoglobin and its color metabolites. It is shown that bleachers of bruises and hematomas consist of water, hydrogen peroxide and sodium hydrocarbonate. When this bleachers of bruises use for intradermal injection there can quickly bleached bruises due to the alkaline saponification of protein-lipid complexes of plasma, cold boiling inside the biological mass and the oxidative discoloration of hemoglobin and its metabolites. Cold boiling and oxidative discoloration inside derma occurs due to the formation of gas of oxygen from hydrogen peroxide under the action of the enzyme catalase. In addition, local hyperthermia increases and accelerates the discoloration of bruises.

Key words: bruises, cosmetics, bleach, hydrogen peroxide, sodium hydrocarbonate, temperature pharmacology. 


\section{INTRODUCTION}

Medical procedures such as drug injections, as well as domestic, sports, tourist and combat injuries, abrasions and wounds are often complicated by bruises in which the skin, mucous membranes and/or nail plates are painted blue for several days 1,2,3,4. The unusual color of these parts of the body gives blood, which permeates the tissue after flowing out of damaged blood vessels5,6. In the first moments, the blood is red, and after a few seconds, the blood turns blue. The fact is that the main dye of the blood is hemoglobin, which changes its color depending on the connection with oxygen or carbon dioxide. Thus, hemoglobin associated with oxygen (oxyhemoglobin) is red, and hemoglobin without oxygen (deoxyhemoglobin) and hemoglobin associated with carbon dioxide (carbohemoglobin) are blue $7,8,9$. At the same time, hemoglobin in erythrocytes is able to reversibly bind to oxygen, so after the flow of blood from the damaged blood vessels into the surrounding tissues, hemoglobin inside the erythrocytes carries oxygen and along the way gives it to the tissues, capturing carbon dioxide from them ${ }^{10}$. Therefore, at normal body temperature in the portion of blood flowing from the damaged vessel, rapidly decreases the content of oxyhemoglobin and increases the content of carbohemoglobin in red blood cells. This leads to a rapid change in blood color from red to blue 11,12,13.
However, there is another explanation for the blue color of the skin in the bruising area. In particular, some believe that the strikes often "rush" vein, and venous blood is blue. Therefore, the output of venous blood in the tissue stains them in blue7,14. Despite different explanations of the nature of blue skin in the area of bruises, there is a consensus that bruises are irrefutable symptoms of injuries and punches with hard blunt objects. So, in traumatology, in forensic medicine and in jurisprudence bruises are unambiguously recognized as symptoms of injuries 1,2,5. However, historically, official medicine does not recognize bruising as an independent disease, and in most areas of medicine bruises are ignored as symptoms of disease. This has led to the fact that modern standards of examination of patients do not require physicians to identify, photograph and monitor the dynamics of size, shape and color of the skin in places of bruises 15,16,17. In this regard, such information is not available in modern statistical reports of medical institutions 18,19. It should be added that until today, official medicine does not offer a means for rapid discoloration of bruises 1,6,17.

Modern medical standards do not contain information about medicines that provide urgent dissolution and discoloration of blood spots and their removal from the surface of medical bandages, instruments, skin and mucous membranes of people ${ }^{16,17}$. There is no medical standard for urgent discoloration of the skin and nail in the area of bruising and hematoma ${ }^{17}$.

However, many people don't believe it, so attempt to "withdraw" a 
bruise. To do this, they use "folk remedies"5,6,20,21. However, their effectiveness is still not high enough. Therefore, the use of these funds does not allow an urgent and completely "remove" bruise ${ }^{1,2,4,5}$.

At the same time, thanks to the success of chemistry, industrial bleachers have long been developed, which are used for bleaching fabrics in the textile industry, for bleaching paper in the pulp and paper industry, for bleaching wood and food in the woodworking and food industries, and so on 22,23,24.

The successful creation of industrial bleaches gives hope for the development of drugs for urgent bleaching and removal of bruises. The fact is that in the field of cosmetology, hematology and dermatology little attention was paid to physical-chemical factors of local interaction of drugs inside the blood portions. In particular, there are no systematic studies devoted to the study of such factors of local interaction of liquid drugs with blood as alkaline, osmotic, local temperature activity and the ability of solutions to form gas bubbles, that is, to boil, in the cold. So, in the field of purulent surgery and otorhinolaryngology it is shown that the most important physical and chemical factors for effective dissolution and removal of the thick pus and sulphurous plugs with help of hydrogen peroxide solutions are: high accuracy of local mechanical and hydrodynamic effects, liquid form, local hyperthermia, local alkalinity and ability to cold boil25,26. However, the importance of these physical and chemical factors for bleaching of skin in the area of bruising at home with help of hydrogen peroxide solutions is not fully understood.

The purpose of the review is to demonstrate the prospects of using hydrogen peroxide to create new bleachers bruises by giving its solutions of certain physical and chemical properties similar to the known bleach textiles, wood, paper, wool and hair in the industry.

\section{Methods}

A thorough search for information on new drugs and methods for discoloring bruising with help of certain physical and chemical factors of local interaction was carried out from 1989 to 30 May 2019 using the databases of the Google Patent, Google Scholar, Scopus and PubMed. In addition, we studied the references and conducted a citation search. At the final stadium of study a systematic review was conducted in accordance with the quality standards described in the AMSTAR measurement tool27 and the PRISMA 2009 checklist28. The search strategy was based on the PICO model29,30. Two co-authors independently selected, evaluated and extracted data. The flowchart for selecting articles was a spiral in which each spiral turn was an iteration 31,32 . Keywords of the strategy of search was the following: bruises, ecchymosises, hematomas, blood, red blood cells, erythrocytes, hemoglobin, bleach, whitening products, whitening methods, cosmetics, hydrogen peroxide, sodium hydricarbonate. The criteria for inclusion of the scientific source were limited to the presence in it of information about the invented drugs and/or methods of their use, which allow due to physical and 
chemical factors of local interaction to urgently discolor erythrocytes and hemoglobin, or blood stains on the surface of textiles or skin, or discolor bruises, a portion of liquid blood or dry blood crust. The criterion for the exclusion of the article was the lack of information about the invented drugs and/or medical technologies that provide for urgent discoloration, dissolution and/or removal of blood spots or discoloration of bruises, red blood cells, hemoglobin or its metabolites in a single local application. The risk of individual bias in judgments was reduced by relying on the essence of the invention as a generally accepted criterion of novelty. A total of 13,110 sources of information were studied, of which only 18 inventions were evaluated for review.

\section{Results}

In the blood vessels of all people flowing blood, which has a red or cherry color. In this case, one part of the people refers to blacks, and the other part - to light-skinned. In this regard, black people's skin is darker than their blood, and light-skinned people's skin is lighter than their blood. Inside the skin and under it are blood vessels through which blood flows. Blood is red in the arteries and blue in the veins. Arteries and veins are elastic tubes, the walls of which are made mainly of translucent white material. In this case, the arteries have a smaller diameter and at the same time thicker walls than the veins. Therefore, arteries are filled with arterial blood, from the outside look less pigmented than the veins. In this regard, ceteris paribus arteries with arterial blood have less effect on skin color than veins with venous blood.

Another thing is when the blood goes beyond the blood vessels, penetrates the skin and forms bruises. In the area of bruises on the skin of white people there are pigment spots, the color of which little depends on what kind of blood poured into the skin: venous or arterial.

It was found that the color of blood depends mainly on the color of red blood cells, which occupy almost half of its volume $4,5,7$. Individual isolated red blood cells normally have a yellow-green color, but in their mass (in the aggregate, that is, collected in a pile as in blood plasma), they acquire a darker color10,11. In particular, a group of red blood cells may have a bright scarlet color, red color, dark red color, and sometimes cherry blue color8,9,10. The color of the mass of red blood cells depends on the stage of their development and the color of the respiratory pigment hemoglobin 11,12,13,14. Thus, erythroblasts in the early stages of their development have a blue color; later erythroblast cells become gray, and red color they acquire only after fully mature ${ }^{33}$. In turn, the respiratory pigment hemoglobin may have a bright red, dark red and blue color $9,10,11,13,14$. The fact is that the color of hemoglobin is determined by its connection with gases. Thus, hemoglobin associated with oxygen (oxyhemoglobin) has a red color, hemoglobin associated with carbon dioxide (carbohemoglobin) has a blue color, and hemoglobin associated with carbon monoxide (carboxyhemoglobin) has a bright scarlet color ${ }^{10,11}$. At the same time, inside the skin, however, as well as 
inside other tissues, oxyhemoglobin is easily and quickly released from oxygen, binds to carbon dioxide and turns into carbohemoglobin. So all bruises are blue $8,9,11$. It is believed that at the same time a few hours under the action of enzymes hemoglobin begins to break down and turns into verdoglobin. Verdoglobin also has a blue color. Then, after 4 to 5 days, verdoglobin turns into biliverdin, which is green. Therefore, in this period of time the bruises takes on a green color. After another 1-2 hours under the action of enzymes, biliverdin is metabolized into bilirubin, which has a yellow color. So at the end of its existence, the bruises becomes yellow. Then gradually the bilirubin is excreted in the blood from the site of the injury and the bruise disappears ${ }^{34}$.

Therefore, for reliable discoloration of the skin in the area of bruise, no matter how much time has passed since its appearance, you should look for a tool that can discolor carbohemoglobin, oxyhemoglobin, verdoglobin, biliverdin and bilirubin.

However, usually in normal conditions in the first hours and in the first few days the main dye skin in area bruises is carbohemoglobin. From this it follows that for urgent discoloration of the skin in the area of bruises we need to find a remedy that can discolor carbohemoglobin.

It is shown that people have long learned to discolor textiles, wool, paper, wood and leather in the industrial sphere. These natural products lose their natural color and become white under the action of specially developed solutions. The majority of these solutions is an aqueous solution of hydrogen peroxide with special physical and chemical properties ${ }^{23,24}$.

The analysis of compositions of industrial bleaching liquids used for discoloration of natural products of animal and vegetable origin was carried out. As a result, it turned out that all these liquids are aqueous solutions of several groups of substances soluble in water. Therefore, it should be recognized that the main ingredient is water. The second mandatory component is hydrogen peroxide. Hydrogen peroxide is the chemical compound $\mathrm{H}_{2} \mathrm{O}_{2}$. Hydrogen peroxide is a highly reactive, strong oxidizing and bleaching (whitening) agent that is classified as corrosive at concentrations higher than $20 \%$. Hydrogen peroxide has numerous nonmedical uses because of these properties.

As an example, consider the compositions of industrial hair bleaches specified in the modern guide to Industrial Dies23,24. For hair bleaching aqueous solutions of oxidants are used. Most often, hydrogen peroxide is used as an oxidizer. Bleaching action of hydrogen peroxide increase with a combination of such compounds, as peroxosulfates, peroksohydrate carbamine, peroksohydrate sodium and sodium carbonate. It is shown that the degree of hair discoloration efficiency depends on the oxidant concentration, temperature level, $\mathrm{pH}$ value and duration of local interaction. It is shown that an increase in the concentration of hydrogen peroxide and/or its agonists, an increase in the local temperature, an increase in the alkalinity of the solutions above the $\mathrm{pH} 7.0$ 
and an increase in the duration of the interaction enhances the bleaching effect of oxidants. It is shown that the bleaching effect of hydrogen peroxide can be enhanced by its combination with peroxosulfates, carbamine peroxide, sodium peroxohydrate, sodium peroxodisulfate,

potassium peroxodisulfate, ammonium peroxodisulfate, sodium carbonate, ammonia and silicate. Conversely, reduce the bleaching effect of hydrogen peroxide metal ions, especially iron salts.

In conclusion, it should be noted that long-term practice indicates complete safety for human products and things bleached with hydrogen peroxide.

In addition to industrial bleaching of various household items, hydrogen peroxide is used to bleach food products, in particular seafood. Thus, it is reported that to improve the appearance of the spoiled goods, aqueous solutions of hydrogen peroxide are used to bleach seafood such as squids, octopuses and cuttlefish ${ }^{35}$. In addition, hydrogen peroxide can be used to disinfect the water in which the fish swims, in order to protect the fish from infection. It is indicated that fish remains safe for humans when taken orally. In particular, the FDA-approved product, 35\% PEROXAIDß (Eka Chemicals, Marietta, Georgia), is available at a strength of $35 \%$ weight/weight (e.g., $35 \%$ active ingredient). Over-the-counter products used for human health are typically sold at $3 \%$ active ingredient ${ }^{36}$.

Today we can recognize that one of the first developments designed for bleaching textile products, highly demanded in the medical field, is the invention of a "Method for rapid removal of blood stains from clothing" (RU Patent 2371532) 37,38 . This invention was patented in 2009.

The essence of this invention lies in the fact that it was first proposed to use a special washing liquid for quick discoloration of clothing. This liquid represents an aqueous solution of hydrogen peroxide or its water soluble source of from 0.01 to $15 \%$ and agent that removes pollution from 0.01 to $20 \%$ of the total weight of the composition with a $\mathrm{pH}$ of more than 7.0 at the level of its osmotically activity below 140 mosmol/l of water and with a local temperature in the range from +26 to $+42^{\circ} \mathrm{C}$. It should be added that it was proposed to remove the blood stain from the clothes on the human body. For this purpose under the blood-stained site of clothes is enclosed the absorbing napkin. This napkin is placed its waterproof layer on the surface of the human body. Then the bloodstained area of clothing is continuously washed and rubbed with a sponge impregnated with a special washing liquid specified above, until the transformation of the color of the spot from red to yellow. After that, the used napkin is replaced with a new napkin, and the bloody area of clothing is impregnated with bleaching liquid for up to 2 seconds. Washing is carried out for 2 seconds by 2 - fold impregnation of clothing with washing liquid with a sponge. After washing, the napkin is removed outside and the fabric is immediately dried with drying wipes and a stream of warm dry air.

It is shown that due to alkaline, local hyperthermia and hypo-osmotic activity, 
this solution allows to remove blood stains urgently due to erythrocyte hemolysis. The proposed bleaching agent excludes coagulation of blood proteins and sticking them to the tissue, since even the blood that has been overthrown is washed and melted in an alkaline medium. Increasing the local temperature to the level of $+42{ }^{\circ} \mathrm{C}$ provides an increase in the efficiency of washing clothes from blood elements, accelerates the hemolysis of red blood cells in the hypo-osmotic liquid aqueous medium at the level of its osmotic activity below $140 \mathrm{mosmol} / \mathrm{l}$ of water with the exception of temperature coagulation of blood proteins by eliminating excessive local hyperthermia. Acceleration of hemolysis of red blood cells provides acceleration of washing clothes from hemoglobin, which is the main carrier in the blood of its red color. In turn, the acceleration of washing clothes from blood residues, and in particular from hemoglobin provides after that the possibility of rapid application of a bleaching solution.

Washing the area of clothing, stained with blood, in the conditions of rubbing until the disappearance of the red color and its transformation into yellow color increases the speed of removal of blood residues from clothing. Due to the effective mechanical removal of blood residues before applying the bleaching solution increases the efficiency of its application and the speed of achieving complete whitening.

Consequently, in industry, veterinary medicine and fishing for bleaching paper, wood, cotton, linen, leather, wool products and seafood, as well as in the field of hygiene for bleaching hair and bloody clothes on the human body using aqueous solutions of hydrogen peroxide. However, in industry, veterinary and fishing as a universal bleach solution is used mainly solution 3 - 30\% hydrogen peroxide. In household conditions with cosmetic and hygienic purpose in the role of bleach hair and clothing used solution of $3 \%$ hydrogen peroxide. It is shown, that water containing hydrogen peroxide in a concentration of up to $20 \%$ has a pronounced local discoloration effect and does not have an aggressive effect for human cutaneous.

Bruising is a consequence of the release of red blood cells from the blood vessels in the tissue. Visible to the eye tissue staining occurs due to the release of red blood cells into the skin or subcutaneous fat. Most often this occurs due to injuries and mechanical damage to blood vessels 4,5 . It is believed that veins are damaged more often. So the tissues are impregnated with venous blood and that is why the bruises have a dark cherry color. Moreover, often the area involved changes its color very quickly from dark cherry to dark purple, and sometimes to black and blue. However, the color dynamics does not stop there. After a few days the color of the tissue in the area of the bruise becomes green and then yellow as the hemoglobin is degraded to bilirubin 39,40 .

Bruises give the skin an ugly color, often bruises have an unsightly shape. In addition, sometimes bruises are accompanied by swelling, soreness and local hyperthermia. All this spoils the aesthetic result. However, official 
medicine does not recognize bruises as an independent disease 18,19 and there are still no special drugs that quickly discolor the skin in the area of bruises 1,6,17. It is recognized that the bruises are mainly cosmetic and temporary problem, as usually most bruises dissolve without a trace and on their own. Therefore, to improve the color of the skin in the area of bruises used mainly anti-inflammatory and folk remedies. These products are applied directly to the skin in the area of bruises. It is generally recommended to impose on the area of the bruise with the ice, a solution of corticosteroid or a solution of epinephrine with the local anesthetic, as well as solutions, gels, ointments and creams with vitamin means. Of vitamin most popular vitamin K. In addition are often recommended infusions and decoctions of medicinal plants such as Arnica, Montana and Melilotus 41,42,43.

However,

all

these recommendations do not lead to fast and reliable bleaching of bruises. Moreover, the discoloration of the skin in the area of bruises with these funds is still questionable among doctors and specialists in the field of pharmacology 44,45 . That is why the search for effective and reliable means of bleaching bruises is not completed.

Today we can say that the purposeful search for new drugs that can quickly whiten bruises, was started in the early 21 st century. In 2009 it was patented "Methods of diagnostics and treatment of clotted hemothorax by A.Y.Malchikov" (RU Patent 2368333) in whom was reporting about that heated to $37{ }^{\circ} \mathrm{C}$ a solution of $5 \%$ sodium hydr4ocarbonate and $1.5 \%$ hydrogen peroxide dissolves clotted blood in the pleural cavity in hemothorax. In 2010 it was the first reporting about a case in which $15 \%$ hydrogen peroxide carbamide gel minimized the discoloration and discomfort associated with bruising ${ }^{44}$. It has been shown that skin pigmentation in the area of ecchymosis decreased due to application to the skin under occlusion with an adhesive bandage, a hydrated gel contained hydrogen peroxide $\left(\mathrm{H}_{2} \mathrm{O}_{2}\right)$ 5 to $20 \%$ or carbamide peroxide $\left(\mathrm{CH}_{6} \mathrm{~N}_{2} \mathrm{O}_{3}\right.$, hydrogen peroxide combined with urea).

The bleaching effect of hydrogen peroxide on hemoglobin became known much earlier. In particular, in 1982 it was shown that the bleaching effect of hydrogen peroxide is associated with the hemolysis of red blood cells and with the destruction of light-absorbing double bonds inside the colored pigments ${ }^{46}$.

Very soon it was shown that the true bruises are manifested by visible eye staining of tissues in red-blue color and are not accompanied by local hyperthermia ${ }^{47}$. It was found, that the "dye" of tissues in the area of bruises is blood, which does not have a local irritant effect. In particular, with the help of infrared thermography, the dynamics of local temperature was studied and it was shown that intradermal and subcutaneous blood injection does not lead to local hyperthermia.

In this regard, for accurate differential diagnosis of abrasions, soft tissue contusions and bruises, it was proposed to determine the local temperature of the damaged surface using infrared thermography. So the 
invention was developed «Persons infrared differential express-diagnostics of bruising and injury of soft tissuesı (RU Patent 2577510).

In 2015, for the first time it was proposed to whiten bruises by intradermal injection of a special solution - first invented "Bruise bleacher" (RU Patent 2539380).

The first bleacher of bruises was solution with $0.03-0.01 \%$ hydrogen peroxide, $\quad 1.8 \%$ sodium hydrogencarbonate and $0.25 \%$ disodium salt of ethylenediaminetetraacetic acid. This tool is able to extract iron from its insoluble salts and to form a chelate connections with the iron without the formation of gas bubbles and without providing a denaturing action on the cells of the skin and subcutaneous fat and no toxic effect on the human body. It was shown, that the proposed remedy provides conditions of biophysical (electrophysiological) rest for cells, since the concentration of extracellular sodium cations corresponds to the concentration accompanying electrophysiological "rest potential" in the membranes of cells of our body. The sodium hydrogen carbonate in the proposed concentration creates a physiological analogue of "hydrogen carbonate" buffer gives the solution a stable alkaline activity in the range $\mathrm{pH} 8.4$, the ability to liquefy fat, blood, intercellular fluid, lymph, and improves the diffusion of the aqueous solution in the skin and in the subcutaneous adipose tissue, accelerates the resorption of the medicamental infiltration, appearing in the tissue at the intradermal and/or subcutaneous injection of drugs. In this case the alkaline solution does not cause alkaline burns of the tissues. Hydrogen peroxide in the proposed concentration gives the solution sufficient oxidative activity, but excludes the formation of oxygen gas bubbles during injection of the solution into the skin and/or subcutaneous fat in the area of bruising, that is, excludes cold boiling in the tissues when injected into them.

Then, immediately after the demonstration of this new possibility, the formulation of the first bleach of bruises was modified and the development of its application for discoloration of the skin in the area of bruising was started. In particular, "Bleaching agent" (RU Patent 2589682), "Agent for intradermal bruise whitening" (RU Patent 2573382), "Method of skin discoloration in the area of bruising" (RU Patent 2582215) "Method for skin discoloration in bruising area" (RU Patent 2586278) were invented.

After modification bleach of bruises remained an aqueous solution for injection in which the main ingredients were $0.01-0.03 \%$ hydrogen peroxide, 1.7 or $1.8 \%$ sodium hydrogen carbonate and 0.125 - $0.250 \%$ lidocaine hydrochloride. Technology of skin discoloration in the area of the bruise was also a little bit fleshed out. First, it was proposed to use a solution heated to a temperature of +37 $+42{ }^{\circ} \mathrm{C}$. Secondly, it was recommended to introduce a warm solution into the skin by injection until the formation of the entire area of the bruise effect of a colorless lemon crust. At the end of the procedure of bleaching the bruise, it was recommended to make a vibrational local hyperthermia massage of the skin in 
this place until the complete resorption of the infiltrate.

Then in 2016 it was patented the invention "Method of removing paint from skin" (RU Patent 2600504). The essence of this invention is that for to remove paint from skin repeatedly pierced with injection needle and in openings successively introduced metal scaler with an antiseptic solution at a pH of $7.4-8.5$ and a local hyperthermia of $+37-+42^{\circ} \mathrm{C}$ and on the scaler gives for the longitudinal oscillations with a frequency of $25-43 \mathrm{kHz}$.

However, intradermal injection of the bleach solution bruising threat. The fact that the injection needle with a puncture of the skin can damage the blood vessels, that can cause interstitial bleeding, hemorrhage, bruising, inflammation, abscesses and sepsis. Therefore, it was decided to discolor bruises and blood stains without injection. In 2017 there were reports of such a possibility. In particular, there were reports about the following invention: "Method for emergency bleaching and blood crust removal from skin in place of squeezed out acne" (RU Patent 2631593), "Means for intravital skin whitening near blue eyes" (RU Patent 2639485) and "Method for whitening of bruise under eye" ( RU Patent 2639283). The essence of these inventions is that for discoloration of traces of blood on the skin and inside the skin (with bruises) it is proposed to use a warm solution of bleachers bruises externally using a warm compress. At the same time, a solution of hydrogen peroxide and sodium hydrogen carbonate was supplemented with a local anesthetic that easily penetrates through intact skin. In particular, lidocaine hydrochloride was proposed as such a local anesthetic. Thus, modified the recipe of the bleach bruising. A local anesthetic that easily penetrates the skin gave the bleach solution of bruises a local anti-inflammatory effect.

Almost at the same time, several more bleaching medicines have been developed for external use. First, it was invented "Bleaching opener of dried blood for wrapping bandages adhered to a wound" (RU Patent 2653465). This drug is also intended for external use, namely - for fast and safe softening of the bandage glued to the surface of the wound. The invented tool is an aqueous solution that contains $0.75-1 \%$ hydrogen peroxide, $\quad 1.2 \%$ sodium hydrogen carbonate and $0.5 \%$ lidocaine hydrochloride. It is shown, that the solution of this agent has optimal osmotic, alkaline, buffer, foaming, washing, analgesic and bleaching activity. Therefore, this drug provides effective and safe sanitation of wounds, softening of blood crusts on the bandage, bloodless and painless removal of the bandage from the wound.

Second, it was invented "Decolorant of blood" (RU Patent 2647371). This medicine is intended for external use only. It is an aqueous solution that contains hydrogen peroxide $-3 \pm 0.3 \%$ and sodium hydrogen carbonate - in an amount that provides saturation of the liquid and the preservation of the precipitate at a temperature of $+42{ }^{\circ} \mathrm{C}$. With local interaction with the blood and/or blood residues, the invented tool very quickly completely dissolves, discolours and removes them. It is shown 
that this blood bleach is intended for urgent bleaching and removal of a portion of fresh blood on the surface of laboratory utensils, old and dry blood stains on clothes, gloves, medical instruments, bandages, as well as on hair, skin and mucous membranes in places of injuries, bruises, abrasions and surgical incisions. It is shown that this blood bleach provides complete discoloration of blood spots 30 seconds after the start of local interaction.

Then the "Method for whitening of sore under nail" (RU Patent 2631592), "Method for blue nail treatment" (RU Patent 2641386) and "Method of emergency bleaching of the skin hematoma under the eye" (RU Patent 2679334) were invented. The essence of these new medical technologies is that a solution of $3 \%$ hydrogen peroxide and $10 \%$ sodium hydrogen carbonate is used as a blood bleach, which at a temperature of $+37-+42{ }^{\circ} \mathrm{C}$ is first used inside the hematoma, and then externally (almost immediately after the bleaching of the hematoma cavity) ${ }^{45}$. The drug is used in a dose that provides complete discoloration of the tissues inside the hematoma cavity. After complete bleaching of the hematoma immediately the same solution is used externally with a warm compress. The compress is superimposed on 10 - 15 minutes. It is shown that usually a single application of this technology provides rapid and complete discoloration of the hematoma under the nail and in the skin.

In addition, it was invented the "Method of screening bleachers bruising" (RU Patent 2634268), the essence is to assess the bleaching activity of drugs in the laboratory using a new biological model. In the role of such a model, it is proposed to use an isolated viable piece of skin of the anterior abdominal wall of a pig with artificial bruises. Artificial bruises are created by intradermal injections of pig's blood an isolated segment of the anterior abdominal wall.

It is shown that the invented bleachers bruising different from all of the drugs in two peculiar properties. The first, they differ in their ingredients (it is water, hydrogen peroxide and sodium hydrogen carbonate), which are well-known and safe medicinal and edible means. Secondly, they differ in physical and chemical properties (it is a mild alkaline, osmotic, oxygen-forming and hyper temperature activity), which are inherent in all universal detergents, solvents and bleaching agents 48 . These features of the composition and activity give the drugs a special pharmacological activity: the drugs have a pronounced nonspecific local effect on protein and protein-lipid complexes, which contain hemoglobin and/or its metabolites, as well as the enzyme catalase. The fact that bleachers bruises an the local interaction cause physical-chemical and aerohydrodynamic destruction, dissolution and discoloration of the dense conglomerate (clot) of coagulated and/or dried blood, which occurs at the boundary of the separation of media.

It was found that the mechanism of action of bleachers bruises is that they cause alkaline saponification, oxygen oxidation and bleaching of colored proteins and protein-lipid complexes (in particular, plasma, blood cells, hemoglobin and its metabolites).This 
saponification provides sodium hydrogen carbonate, and oxidation by oxygen and bleaching provides hydrogen peroxide. The fact that sodium hydrogen carbonate is an effective alkaline buffer, and hydrogen peroxide is a "battery" of gas oxygen $\left(\mathrm{O}_{2}\right)$, which is released from the bound state under the action of blood catalase. It was found that the intensity of the formation of molecular oxygen and bleaching depends on the activity of catalase, the concentration of hydrogen peroxide and the local temperature of the medium. Therefore, in case of excessive concentration increase of hydrogen peroxide can cause intensive formation of foam and gas embolism, and a decrease in the concentration of hydrogen peroxide can exclude the formation of foam ${ }^{49}$. Therefore, all other things being equal, the concentration of hydrogen peroxide in the solution is increased to enhance the cold boiling process up to strong gurgle and the geyser effect and vice versa.

It should be noted that to date, no official studies have been conducted on the safety of aqueous solutions of hydrogen peroxide and peroxide gels for bruises. However, peroxides are widely used in medical institutions. In particular, a solution of $3 \%$ hydrogen peroxide is sold in pharmacies without a prescription as a local antiseptic; A solution of $5 \%$ hydrogen peroxide is used to bleach hair; A solution of $6.5 \%$ carbamide peroxide is used as an over-the-counter softener of earwax; A solution of carbamide peroxide at a concentration of $5-20 \%$ is widely used in dentistry for teeth whitening 50,51 .
However, the U.S. Food and Drug Administration (FDA) in its code of Federal Regulations states that hydrogen peroxide is "generally recognized as safe" as a bleaching agent52.

Consequently, the combination with each other of such well-known drugs as water, sodium hydrogen carbonate and hydrogen peroxide, allows to create new cosmetics that provide rapid whitening of the skin and nail plates in the area of bruises and bruises ${ }^{53,54}$.

\section{Conclusion}

It was found that the blood stains the skin in the bruise due to the fact that it contains red blood cells, which contain a colored protein hemoglobin. Immediately after the outflow of blood vessels in the tissue erythrocytes remain intact, they give the tissues the remnants of their oxygen and their hemoglobin in the absence of oxygen becomes blue. However, after a few days, red blood cells die, their shell breaks, hemoglobin remains defenseless and is influenced by enzymes. A few days hemoglobin is converted first to the metabolites in green and then - in metabolites with yellow color. It is shown that the blood does not have a local irritating effect on the skin and subcutaneous fat, so usually bruises are not inflamed, and their unpleasant color disappears independently after a few days. It is believed that bruises are not a disease, but a banal cosmetic problem, because they worsen the aesthetic color of the skin with their color and shape ${ }^{53}$. However, there are no drugs that quickly discolor the skin in the area of bruises. At home, often used ice pack, steroid anti-inflammatory drugs, 
vitamin preparations and homeopathic remedies in the form of infusions and decoctions of medicinal plants.

Therefore, when bruised, to improve the cosmetic result of traditionally used medicines, which do not discolor the hemoglobin and its colored metabolites. At the same time, industrial bleaches, which are aqueous solutions of hydrogen peroxide, are used for bleaching hair, skin, paper, wood and seafood. It is shown that the bleaching action of hydrogen peroxide can be enhanced by increasing its concentration in the solution by increasing the temperature and $\mathrm{pH}$ of the solution by increasing the interaction time, and by combination with such reagents as peroxosulfates, peroksohydrate carbamine, peroksohydrate sodium, peroxodisulfate sodium, ammonia or silicate and carbonat sodium. It is noted that metal ions, especially iron salts, reduce the bleaching effect of hydrogen peroxide.

So, it was until 2009, when there was an invention created for urgent discoloration of blood stains on clothes. It was first proposed to apply an externally warm alkaline solution of hydrogen peroxide to discolor blood stains. In the following years, there were reports of several new drugs and ways to use them for emergency discoloration of the skin in the area of bruises. Analysis of the composition of these drugs showed that they are all alkaline solutions of hydrogen peroxide, intended for external use with a help a warm compress or for intradermal injection until the appearance of the effect of lemon crust on the entire area of the bruise. As a safe and effective alkaline agent, the authors proposed the use of sodium hydrogen carbonate.

In chronological order are the invented formulation of cosmetic products with special physical-chemical properties that in the local interaction with the skin in the area of the bruise quickly dissolves the crust of dried blood, discolor the blood and her tracks and lead to a complete removal of residual blood from the treated surface. It is shown that new cosmetics have been patented in Russia under the names "Bleacher bruises", "Bleaching agents" and "Blood bleachers". In addition, it was invented the original technology to use bleaches for immediate discoloration of the skin and nail plate in the area of bruising and hematoma. For skin discoloration it is proposed intracutaneous injections of solution of a bleaching agent with 0.01-0.03\% hydrogen peroxide and 2 - 4\% sodium hydrogen carbonate. For discoloration of the nail plates it is proposed injected to bring in subungual hematomas solutions bleaches with 3\% hydrogen peroxide and $10 \%$ sodium hydrogen carbonate. Moreover, in all cases it is recommended to combine injections with local hyperthermia at a temperature of +42 ${ }^{\circ} \mathrm{C}$.

Additional studies are needed to assess the safety and efficacy of treating bruises with aqueous solutions and hydrogen peroxide gels. Additional tests may include a biopsy of the treated and untreated plots bruises; placebocontrolled, blind studies; measurement of hemoglobin before and after treatment of large bruises to demonstrate safety; the evaluation of changes in 
pigmentation and the skin's integrity; the assessment of the depth of penetration; and other applications for local peroxide gels under occlusion.

Limitations of study could have been present due to the inclusion only inventions based on physical and chemical factors of local interaction. Additionally, the included inventions were pioneering and scanty in this field. These methodological considerations should be expanded in the future.

\section{Financial Support and Sponsorship} Nil.

\section{Conflicts of Interest}

There are no conflicts of interest.

\section{REFERENCES}

Current Medical Diagnosis and Treatment 2012, Fifty-First Edition. Ed. McPhee SJ, Papadakis MA, Rabow MW. New York, Chikago, San Francisco, Lisbon,London, Madrid, Mexico City, Milan, New Dely, Juan, Seoul, Singapore, Sydney, Toronto.San Lange Medical Book. 2012.

Hamman MS, Goldman MP. Minimizing bruising following fillers and other cosmetic injectables. J Clin Aesthet Dermatol. 2013; 6(8): 16-18.

King $\mathbf{M}$. The management of bruising following nonsurgical cosmetic treatment. J Clin Aesthet Dermatol. 2017; 10(2): E1-E4.

Johnson J. How to tell if it is a bruise or a blood clot. Reviewed by Judith Marcin. Available from: https://www.medicalnewstoday.com/arti cles/322829.php. [Last accessed on 2019 Feb 1].

Villines Z. What to know about bruising easily. Reviewed by J. Keith Fisher. Available from: https://www.medicalnewstoday.com/arti cles/325525.php. [Last accessed on 2019 May 30].

Leu S, Havey J, White LE, et al. Accelerated resolution of laser-induced bruising with topical 20\% arnica: a raterblinded randomized controlled trial. $\mathrm{Br} \mathrm{J}$ Dermatol. 2010; 163 (3): 557-563.

Kienle A, Lilge L, Vitkin IA, Patterson MS, Wilson BC, Hibst $\mathbf{R}$, Steiner $\mathbf{R}$. Why do veins appear blue? A new look at an old question. Applied Optics. 1996, 35 (7): $1151-1160$.

Pittman RN. Regulation of Tissue Oxygenation. San Rafael (CA): Morgan \& Claypool Life Sciences; 2011.

Severinghaus JW. Blood gas calculator. J Appl Physiol. 1966; 21: 1108-1116.

18.3 Erythrocytes - Anatomy and Physiology - BC Open Textbooks. Available from: https://opentextbc.ca/anatomyandphysi ology/chapter/18-3-erythrocytes. pdf. [Last accessed on 2019 May 10].

Franco RS,M. Puchulu-Campanella $E$, Barber LA, Palascak MB, Joiner CH, Low PS, Cohen RM. Changes in the properties of normal human red blood cells during in vivo aging. Am J Hematol. 2013; 88(1): 44-51. 
Mairbäurl H. Red blood cells in sports: effects of exercise and training on oxygen supply by red blood cells. Front Physiol. 2013; 4: 332.

Mairbäurl H, Weber RE. Oxygen transport by hemoglobin. Compr. Physiol. 2012;2: 1463-1489.

Hughes VK, Ellis PS, Burt T, Langlois NE. The practical application of reflectance spectrophotometry for the demonstration of haemoglobin and its degradation in bruises. J. Clin. Pathol. 2004; 57(4): 355359.

Best health outcomes for Pacific Peoples: Practice implications. A resource booklet prepared for the Medical Council of New Zealand by Mauri Ora Associates. Available

from: https://www.mcnz.org.nz/assets/standard s/349b83865b/Best-health-outcomes-forPacific-Peoples.pdf. [Last accessed on 2019 May 10].

Standard treatment guidelines and essential medicines list. The United Republic of Tanzania. Ministry of Health and Social Welfare. Fourth Edition. May, 2013. Available from: https://www.who.int/selection_medicines /country_lists/Tanzania_STG_052013.pdf. [Last accessed on 2019 May 10].

International Statistical Classification of Diseases and Related Health Problems. (The) ICD-10. 10th Revision. V. 1 -3. 2010 Edition. World Health Organization. 20102016.
Gear HS, Biraud Y, Swaroop S. International work health in statistics. 1948-1958. World Health Organization. Palais des Nations. Geneva. 1961.

Conference on Modern Statistics for Modern Society. Methodologies and Working papers. 6 - 7 December 2007. 2008 edition. Luxembourg: Eurostat. 2008.

Effective Home Remedies For Bruises. Available from: https://www.stylecraze.com/articles/effe ctive-home-remedies-for-bruises/\#gref [Last accessed on 2019 Jan 30].

10 Ways to Get Rid of Bruises. Available from:

https://www.healthline.com/health/howto-get-rid-of-bruises. pdf. [Last accessed on 2019 Jan 30].

Biermann CJ. Essentials of Pulping and Papermaking. San Diego: Academic Press, Inc. 1993.

Industrial Dyes: Chemistry, Properties, Applications. Edit. K. Hunger. Third, Completely Revised Edition. 2003 WILEY$\mathrm{VCH}$ Verlag $\mathrm{GmbH} \& \mathrm{Co}$. KGaA, Weinheim. 2003.

Marzec A. The effect of dyes, pigments and ionic liquids on the properties of elastomer composites. Polymers. Université Claude Bernard - Lyon I, 2014. English.

\section{Urakov A, Urakova N, Reshetnikov A, Kopylov M, Chernova L. Solvents of pus- medicines with physical-chemical aggressive action. IOP Conf. Series:}


Journal of Physics: Conf. Series. 2017; 790: 012033.

Urakov A, Urakova N, Chernova L. Possibility of dissolution and removal of thick pus due to the physical-chemical characteristics of the medicines. Journal of Materials Science and Engineering B. 2013; $3(11): 714-720$.

Shea BJ, Grimshaw JM, Wells GA, Boers $M$, Andersson N, Hamel C, Porter AC, Tugwell $P$, Moher D, Bouter LM. Development of AMSTAR: a measurement tool to assess the methodological quality of systematic reviews. BMC Med Res Methodol. 2007; 7:10.

Moher D, Liberati A, Tetzlaff J, Altman DG. Preferred reporting items for systematic reviews and meta-analyses: the PRISMA statement. PLOS Med. 2009 Jul 21; 6 (7): e1000097.

Miller SA, Forrest JL. Enhancing your practice through evidence-based decision making: PICO, learning how to ask good questions. J Evidence-Based Dental Pract. 2001; 1 (2): 136-41.

Eriksen MB, Frandsen TF. The impact of patient, intervention, comparison, outcome (PICO) as a search strategy tool on literature search quality: a systematic review. J Med Libr Assoc. 2018; 106(4): 420-431.

Boehm B. Spiral Development: Experience, Principles, and Refinements. Spiral Development Workshop. February 9, 2000, edited by Wilfred J. Hansen July 2000. http://www.sei.cmu.edu/reports/00sr008. pdf [Last accessed on 2019 Jan 30].

Alshamrani A, Bahattab A. A comparison between three SDLC models waterfall model, spiral model, and incremental/iterative model. International Journal of Computer Science. 2015; 12 (1): 106-111.

Baron MH, Isern J, Fraser ST. The embryonic origins of erythropoiesis in mammals. Blood. 2012; 119(21): 48284837.

Langlois NE, Gresham GA. The ageing of bruises: a review and study of the colour changes with time. Forensic Sci. Int. 1991; 50(2): 227-238.

Italy is bleaching old seafood to make it look fresh. Available from: https://www.vice.com/en_us/article/gvk $\mathrm{mgq} /$ italy-is-bleaching-old-seafood-tomake-it-look-fresh. pdf. [Last accessed on 2019 Aug 14].

Use of hydrogen peroxide in finfish aquaculture. Available from: https://thefishsite.com/articles/use-ofhydrogen-peroxide-in-finfish-aquaculture. pdf. [Last accessed on 2019 Jan 30].

Urakov A, Urakova N. Rheology and physical-chemical characteristics of the solutions of the medicines. Journal of Physics: Conference Series. 2015; 602: 012043.

Urakov AL. Development of new materials and structures based on managed physical-chemical factors of 
local interaction. IOP Conf. Ser.: Mater. Sci. Eng. 2016; 123: 012008.

Bithell TC. Blood coagulation. In: Lee RG, editor. Wintrobe's Clinical Haematology. Philadelphia: Lea \& Febiger; 1993: 566615.

Dinehart SM, Henry L. Dietary supplements: altered coagulation and effects on bruising. Dermatol Surg. 2005; 31: 819-826.

Seeley BM, Denton AB, Ahn MS, Maas CS. Effect of homeopathic Arnica montana on bruising in face-lifts: results of a randomized, double-blind, placebocontrolled clinical trial. Arch Facial Plast Surg. 2006; 8(1): 54-59.

Alonso D, Lazarus MC, Baumann L. Effects of topical arnica gel on post-laser treatment bruises. Dermatol Surg. 2002; 28(8): 686-688.

Xu F, Zeng W, Mao X. The efficacy of melilotus extract in the management of postoperative ecchymosis and edema after simultaneous rhinoplasty and blepharoplasty. Aesth Plast Surg. 2008; 32: 599-603.

Molenda MA, Sroa N, Campbell SM, Bechtel MA, MD, Opremcak EM. Peroxide as a novel treatment for ecchymoses. J Clin Aesthet Dermatol. 2010; 3(11): 36-38.

Urakov AL, Urakova NA, Gadelshina AA. New medicines: the bleachers of bruises, blue nails, hematomas, blood stains and bloody crusts. Australasian Medical Journal. 2017;10 (11): 942 - 943.
Albright RK, White RP. Red blood cell susceptibility to hydrogen peroxide (H2O2) lysis in chronic hemodialysis patients. Clin Exp Dial Apheresis. 1982; 6(4):223-228.

Urakov AL, Ammer K, Urakova NA, Chernova LV, Fisher EL. Infrared thermography can discriminate the cause of skin discolourations. Thermology international. 2015; 25 (4): 209 - 215.

\section{Urakov A, Urakova N, Kasatkin A,} Chernova L. Physical-chemical aggressiveness of solutions of medicines as a factor in the rheology of the blood inside veins and catheters. Journal of Chemistry and Chemical Engineering. $2014 ; 8(01): 61-65$.

Urakov AL. The change of physicalchemical factors of the local interaction with the human body as the basis for the creation of materials with new properties. Epitőanyag - Journal of Silicate Based and Composite Materials. 2015; 67 (1): 26.

Hydrogen peroxide: practical, environmentally friendly and antibacterial (2007-2008) Did you know there were so many uses for hydrogen peroxide? Available from: http://www.usinghydrogen-peroxide.com/ [Last accessed on 2019 Jan 30].

Albright RK, White RP. Red blood cell susceptibility to hydrogen peroxide (H2O2) lysis in chronic hemodialysis patients. Clin Exp Dial Apheresis. 1982;6(4):223-228. 
U.S. Government Printing Office via GPO Access. Code of Federal Regulations, Title 21, Volume 6. Available from: 21CFR582.1366 FDA. [Last accessed on 20191 Jan 30].

Urakov AL. What are bruises? Causes, Symptoms, Diagnosis, Treatment, Remedies. IP Int J Comprehensive Adv Pharmacol 2020; 5(1): 1-5. Doi: http://doi.org/10.18231/j.ijcaap.2020.001.

Urakov AL, Urakova NA. Hydrogen peroxide discolors blood in the cavity of the hematoma under the nail and in the skin over the bruise. Regional blood circulation and microcirculation. 2020;19(2):67-74. (In Russ.) https://doi.org/10.24884/1682-6655-202019-2-67-74. 